\title{
Rewards in an experimental sender-receiver game
}

Citation for published version (APA):

Peeters, R. J. A. P., Vorsatz, M., \& WalzI, M. (2007). Rewards in an experimental sender-receiver game. METEOR, Maastricht University School of Business and Economics. METEOR Research Memorandum No. 019 https://doi.org/10.26481/umamet.2007019

Document status and date:

Published: 01/01/2007

DOI:

10.26481/umamet.2007019

Document Version:

Publisher's PDF, also known as Version of record

\section{Please check the document version of this publication:}

- A submitted manuscript is the version of the article upon submission and before peer-review. There can be important differences between the submitted version and the official published version of record.

People interested in the research are advised to contact the author for the final version of the publication, or visit the DOI to the publisher's website.

- The final author version and the galley proof are versions of the publication after peer review.

- The final published version features the final layout of the paper including the volume, issue and page numbers.

Link to publication

\footnotetext{
General rights rights.

- You may freely distribute the URL identifying the publication in the public portal. please follow below link for the End User Agreement:

www.umlib.nl/taverne-license

Take down policy

If you believe that this document breaches copyright please contact us at:

repository@maastrichtuniversity.nl

providing details and we will investigate your claim.
}

Copyright and moral rights for the publications made accessible in the public portal are retained by the authors and/or other copyright owners and it is a condition of accessing publications that users recognise and abide by the legal requirements associated with these

- Users may download and print one copy of any publication from the public portal for the purpose of private study or research.

- You may not further distribute the material or use it for any profit-making activity or commercial gain

If the publication is distributed under the terms of Article $25 \mathrm{fa}$ of the Dutch Copyright Act, indicated by the "Taverne" license above, 
Ronald Peeters, Marc Vorsatz, Markus Walzl

Rewards in an Experimental Sender-Receiver Game

$\mathrm{RM} / 07 / 019$

JEL code: C72, C73, D83

\section{METE@R}

Maastricht research school of Economics of TEchnology and ORganizations

Universiteit Maastricht

Faculty of Economics and Business Administration P.O. Box 616

NL - 6200 MD Maastricht

phone : ++31433883830

fax : ++31433884873 



\title{
Rewards in an Experimental Sender-Receiver Game
}

\author{
Ronald Peeters $^{\dagger} \quad$ Marc Vorsatz $^{\dagger *} \quad$ Markus Walzl $^{\dagger}$
}

June 12, 2007

\begin{abstract}
We show in a sender-receiver game with strictly opposing interests that rewards enhance trust but do not influence truth-telling. Subjects who reward tend to tell the truth and trust more often in the presence and absence of reward opportunities. The amount of obtained rewards thereby enhances truth-telling.

JEL Classification: C72, C73, D83.

Keywords: Experiment, Rewards, Strategic Information Transmission.
\end{abstract}

\section{Introduction}

It has been analyzed in numerous laboratory experiments how rewards shape the outcome of socio-economic interactions. For example, Dickinson (2001) shows that exogenously fixed rewards in team production help to increase overall efficiency by about $20 \%$; Sefton et al. (2002) examine repeated linear public good games and find that rewards in form of zero-sum transfers increase group allocations temporarily before falling back to the same level as in the control treatment; and, Andreoni et al. (2003) show that if rewards are introduced in

\footnotetext{
${ }^{*}$ Corresponding author.

${ }^{\dagger}$ Department of Economics, Maastricht University, P.O. Box 616, 6200 MD Maastricht, The Netherlands. Email: \{R.Peeters, M.Vorsatz, M.Walzl\}@algec.unimaas.nl. Financial support by Meteor and NWO is gratefully acknowledged.
} 
the Dictatorship Game, the modal offer does not change but the average offer increases by roughly $40 \%$.

Experimental studies on sender-receiver games as an abstraction of problems of truthful accounting, tax compliance, and corporate governance have recently caught attention (e.g., Gneezy (2005), Cai and Wang (2006), and Sánchez-Pagés and Vorsatz (2007)). It is our objective to investigate the effect of rewards in this class of games. The results we find have important implications for organizations: First, truthful reports can to some extend be expected even in the absence of incentives. Second, rewards have a positive future effect on truth-telling. Finally, and perhaps most importantly, rewards may not be the appropriate tool to overcome the problem of truth-telling, since, on the aggregate, the enhanced level of trust increases the incentives to lie and overcompensates the positive effect described before.

\section{Experimental Design and Procedures}

Setting We consider two sender-receiver games with strictly opposing interests. In the baseline environment, nature selects at the beginning the true type of the sender $(A$ or $B)$. It is common knowledge that both types are selected with equal probability. After the sender has learned her type, she has to send one of the following two messages to the receiver: message $A$ ("type $A$ has been selected") or message $B$ ("type $B$ has been selected"). We will say throughout that the sender tells the truth if her message matches with her type, otherwise she tells a lie. After having observed the message of the sender, the receiver decides whether to take action $A$ or action $B$. In case the action of the receiver matches with the true type of the sender, the sender gets 2 and the receiver 6 ECU (Experimental Currency Units). Payoffs are reversed in case the action of the receiver does not match with the true type of the sender. 
We say that the receiver trusts if his action matches with the message, otherwise he distrusts. Hence, the sender (receiver) gets the lower (higher) payoff after the histories truth-trust and lie-distrust and the higher (lower) payoff after the histories truth-distrust and lie-trust.

The rewarding environment extends this setting. In particular, after the baseline environment has been played and after the receiver has observed the true type of the sender, the receiver has to decide whether or not to transfer 1 ECU to the sender. It is straightforward to see that profit-maximizing and fully rational receivers do never transfer money to the sender. Consequently, and following the original insights of Crawford and Sobel (1982), profit-maximizing and fully rational players tell the truth and trust with probability one-half in all sequential equilibria of both environments.

Implementation The experiment was programmed within the z-Tree toolbox (Fischbacher (2007)) and conducted in the computer laboratory at Maastricht University. ${ }^{1}$ All students of the Faculty from Economics and Business Administration were invited via email to register for the experiment. In total we had 5 sessions with 24 subjects each. Subjects received context-free instructions that they could study at their own pace. Clarifying questions were dealt with privately. Before the experiment started every subject had to answer some control questions correctly.

At the beginning of each session, subjects were randomly divided into two groups of twelve. It was common knowledge that the group composition was constant during the experiment and subjects did not learn who else was in their group. In each of the 80 rounds of an experimental session, subjects from the same group were randomly divided in such a way that six subjects were in the same environment. Then, for each environment, three random

\footnotetext{
${ }^{1}$ The program, instructions, and data are available at http://www.personeel.unimaas.nl/m.vorsatz
} 
pairs were formed and, finally, roles (sender and receiver) were randomly assigned within each pair. Subjects knew their actual environment and their actual role before they took the respective decisions but got never feedback about the identity of their match (at the end of a round they learned the true type of the sender, the actions, and the payoffs).

At the end of the session, subjects were paid off (every ECU equaled 0.04 Euro-cents). The average payment was $€ 12.80$ and the typical session lasted about 90 minutes.

\section{Results}

Aggregate Behavior Fig. 1 shows that the transfer rate is highest after truth-trust $(16.54 \%)$ and that it is significantly lower (below $3 \%$ ) for all other histories. The same figure also reveals that the transfer rate after truth-trust decreases from nearly $40 \%$ in the beginning of the experiment to about $10 \%$ later on.

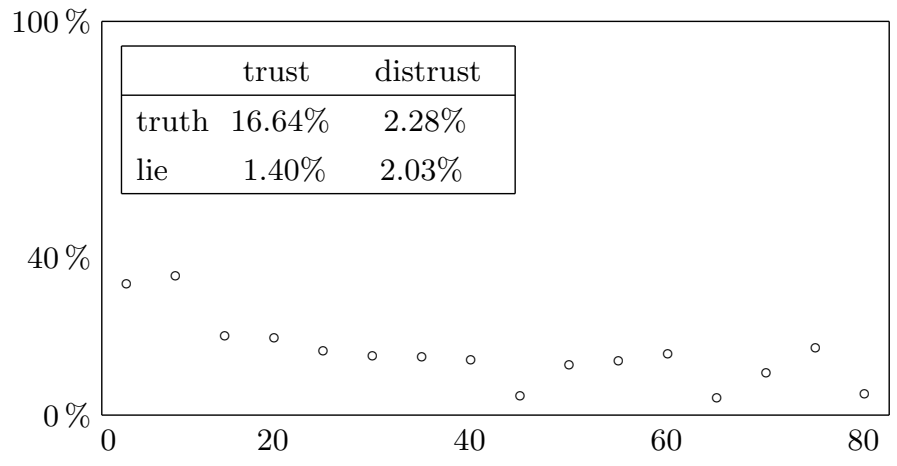

Figure 1: Transfer rates after all histories (table) and 5-round averages after truth-trust.

The experiment of Sánchez-Pagés and Vorsatz (2007) demostrates that, in the baseline environment, senders tell the truth significantly more often than predicted by a sequential equilibrium analysis if the potential payoff distributions are not too unequal. Fig. 2, which presents the percentage of truthful messages over rounds, points into the same direction since 
there is only one instance where the 5-round average is substantially below the equilibrium prediction. This is confirmed by our statistical analysis because the sample median of $54.79 \%$ is significantly greater than $50 \%(p=0.0413$, one-sided $){ }^{2}$ Strikingly, the corresponding sample median for the rewarding environment $(52.92 \%)$ is not significantly greater than $50 \%$ $(p=0.1717$, one-sided $)$. The two sample medians are not significantly different from each other $(p=0.4772$, two-sided $)$.

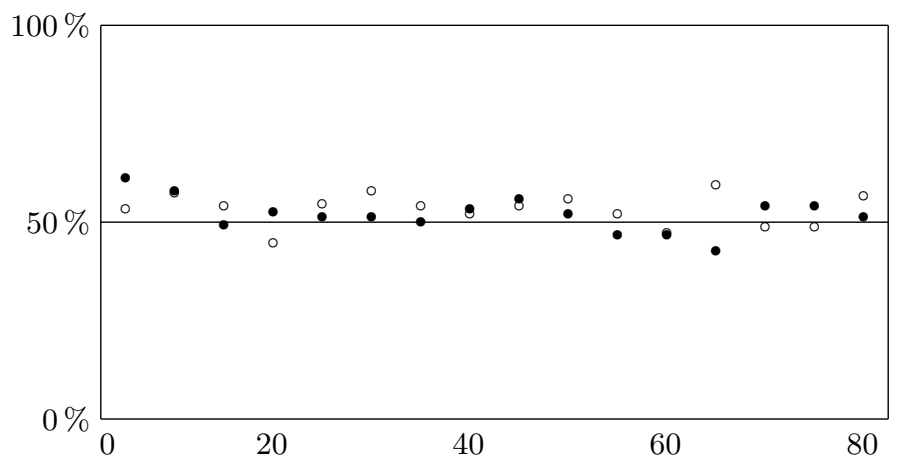

Figure 2: Truth-telling in the baseline (circles) and the rewarding (bullets) environment over rounds (5-round averages).

We observe in Fig. 3 that almost all 5-round averages of the aggregate level of trust are, in both environments, above the equilibrium prediction. We find, however, that the sample median of trust for the baseline environment (51.88\%) is not significantly greater than $50 \%$ ( $p=0.1104$, one-sided $)$. On the other hand, the sample median in the rewarding institution $(57.92 \%)$ is significantly greater than the equilibrium prediction $(p=0.0030$, one-sided $)$ and the sample median of the baseline environment $(p=0.0264$, one-sided).

Type Elicitation We study next whether subjects with different transfer rates show

\footnotetext{
${ }^{2}$ We calculate for every group the overall percentage of the variables of interest (e.g., truth and trust in each environment and differences across environments). This results in ten independent observations, one per group. Next, we apply Wilcoxon signed-rank tests on these observations.
} 


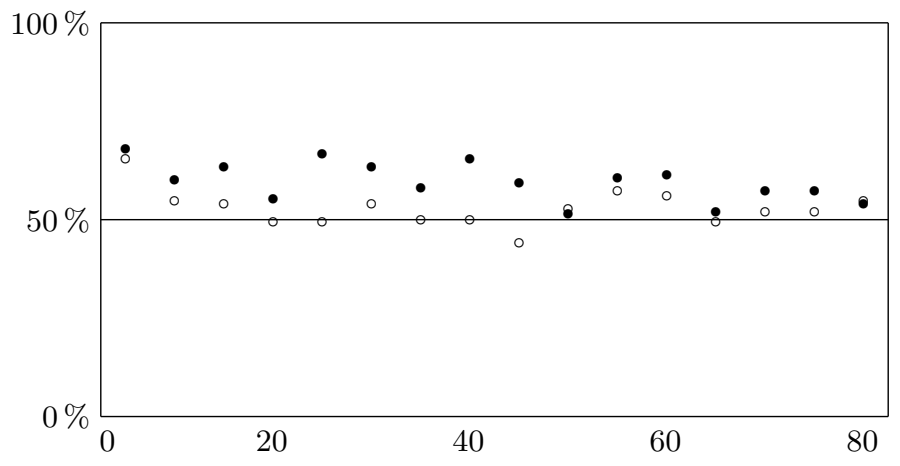

Figure 3: Trust in the baseline (circles) and the rewarding (bullets) environment over rounds (5-round averages).

different behavioral patterns with respect to truth-telling and trust. Since the transfer rate declines initially and we are interested in mature behavior, we exclude all observed transfers from the first twenty rounds. A subject with a transfer rate of at least $75 \%$ after the history truth-trust is said to be a rewarder, provided that the number of transfers is at least 3 . In total 8 out of 120 subjects $(6.66 \%)$ are classified as rewarders. This group of subjects accounts for 41 out of a total of 63 transfers $(65.7 \%)$ and, within this population, the average transfer rate is $91.1 \%$. Additionally, 90 out of 120 subjects (75.0\%) do never make any transfer after the history truth-trust. They are classified as non-rewarders.

\begin{tabular}{llcc}
\hline & & baseline & rewarding \\
\hline truth-telling & all & $53.4 \%$ & $51.8 \%$ \\
& rewarders & $65.1 \%$ & $80.6 \%$ \\
& non-rewarders & $52.4 \%$ & $49.3 \%$ \\
\hline \multirow{2}{*}{ trust } & all & $52.8 \%$ & $59.6 \%$ \\
& rewarders & $61.5 \%$ & $83.1 \%$ \\
& non-rewarders & $54.2 \%$ & $59.9 \%$ \\
\hline
\end{tabular}

Table 1: Overall percentages of truth and trust.

Tab. 1 compares the overall percentage of truth-telling and trust with the rates for the 
rewarders and non-rewarders (considering only the last 60 rounds would not have any statistical effect). We see that, in both environments, rewarders tell the truth and trust more often than the overall population. Wilcoxon signed-rank tests reveal, however, that the difference is only significant for the rewarding environment (the one-sided $p$-values are $0.2982(0.0292)$ and 0.1404 (0.0282) for truth and trust in the baseline (rewarding) environment). ${ }^{3}$ As expected by being a large group, we do not find any significant difference for the non-rewarders (the one-sided $p$-values are $0.3418(0.1411)$ and $0.2386(0.2704)$ for truth and trust in the baseline (rewarding) environment).

Dynamic Effects Our final analysis regards the question whether obtained transfers have a positive effect on the future level of truth and/or trust. To this end we compare the percentage that a subject tells the truth (trusts) when s/he is the next time in the role of the sender (receiver) conditional on whether or not this subject received a transfer after the history truth-trust. Since roles are assigned randomly, we take into account lags of at most 10 rounds.

\begin{tabular}{llcc}
\hline & & baseline & rewarding \\
\hline truth-telling & transfer & $71.3 \%$ & $60.6 \%$ \\
& no transfer & $56.9 \%$ & $54.0 \%$ \\
\hline \multirow{2}{*}{ trust } & transfer & $50.7 \%$ & $69.6 \%$ \\
& no transfer & $52.1 \%$ & $59.1 \%$ \\
\hline
\end{tabular}

Table 2: Conditional percentages of truth and trust.

According to Tab. 2 the percentage of truth-telling is, for both environments, considerably higher if a transfer is obtained. The associated Wilcoxon signed-rank tests reveal that the difference is in fact significant (the one-sided $p$-values are 0.0072 for the baseline and 0.0264

\footnotetext{
${ }^{3}$ Since there are five groups without rewarder, our statistical analysis is here based on less observations.
} 
for the rewarding environment). In the case of trust, the difference is only significant for the rewarding environment (the one-sided $p$-values are 0.5000 and 0.0162 ).

\section{Concluding Remarks}

We found that transfers take place almost exclusively after the history truth-trust. This cannot be explained by standard theories of social preferences such as Fehr and Schmidt (1999) and Bolton and Ockenfels (2000) as they allow rewards to depend on the payoff distribution

only. One interpretation of this result is that those subjects who transfer money regard telling the truth as a kind act worth being rewarded.

At the aggregate level we have seen that positive transfers enhance trust. However, the insight that zero-sum transfers are, if anything, lowering the overall level of truth-telling stands in contrast with results for sanctioning environments because the possibility to costly punish senders tends, if anything, to raise the overall level of truth-telling (see, Sánchez-Pagés and Vorsatz (2007)). Also the group of subjects that punishes a sender after having trusted a lie is about $25 \%$ larger than the group of rewarders. Similar relationships have been found by Offerman (2002) and Brandts and Charness (2003) for different classes of games. The former shows that a more kind action in the hot response game triggers less rewards than a more unkind action triggers sanctions, the latter authors establish that if one player has to announce her/his intended play in a bi-matrix game, a truthful message is rewarded less often than an untruthful message is sanctioned.

Moreover, those subjects who are willing to transfer money are, in both environments, more trustworthy than the overall population. Finally, obtained transfers induce subjects to tell the truth more frequently the next time they are in the role of the sender. 


\section{References}

[1] J. Andreoni, W. Harbaugh, and L. Vesterlund (2003): The Carrot or the Stick: Rewards, Punishments, and Cooperation, American Economic Review 98, 893-902.

[2] G. Bolton and A. Ockenfels (2000): ERC: A Theory of Equity, Reciprocity and Competition American Economic Review 90, 166-193.

[3] J. Brandts and G. Charness (2003): Truth or Consequence: An Experiment, Management Science 49, 116-130.

[4] H. Cai and J. Wang (2006): Overcommunication in Strategic Information Transmission Games, Games and Economic Behavior 56, 7-36.

[5] V. Crawford and J. Sobel (1982): Strategic Information Transmission, Econometrica 50, 1431-1451.

[6] D. Dickinson (2001): The Carrot vs. the Stick in Work Team Motivation Moonlighting, Experimental Economics 4, 107-124.

[7] E. Fehr and K. Schmidt (1999): A Theory of Fairness, Competition, and Cooperation Quaterly Journal of Economics 114, 817-868.

[8] U. Fischbacher (2007): Z-Tree - Zurich toolbox for readymade economic experiments, Experimental Economics 10, 171-178.

[9] U. Gneezy (2005): Deception: The Role of Consequences, American Economic Review 95, 384-394.

[10] T. Offerman (2002): Hurting Hurts More Than Helping Helps, European Economic Review 46, 1423-1437.

[11] S. Sánchez-Pagés and M. Vorsatz (2007): An Experimental Study of Truth-Telling in a Sender-Receiver Game, Games and Economic Behavior, forthcoming.

[12] M. Sefton, R. Schupp, and J. Walker (2002): The Effect of Rewards and Sanctions in the Provision of Public Goods, Mimeo University of Indiana. 


\section{Appendix: Instructions}

Dear participant,

thank you for taking part in this experiment! It will last about 75 minutes. You will be compensated according to your performance during the experiment. In order to ensure that the experiment takes place in an optimal setting, we would like to ask you to follow the general rules during the whole experiment:

- please do not communicate with your fellow students!

- please do not forget to switch off your mobile phone!

- read the instructions carefully. If something is not well explained or any question turns up now or at any time later in the experiment, then ask one of the experimenters. Do, however, not ask out loud, but raise your hand! We will clarify questions privately.

- you may take notes on this instruction sheet if you wish.

- after the experiment, please remain seated till we paid you off.

- if you do not obey the rules, the data becomes useless for us. Therefore we will have to exclude you from this experiment and you will not receive any compensation.

Your decisions are anonymous. None of your fellow students nor anybody else will ever learn them from us.

\section{Environment 1}

The central situation of the experiment is the situation depicted in Figure 1 with the following underlying story.

\begin{tabular}{|c|c|}
\hline \multicolumn{1}{c}{$A$} & $B$ \\
\hline $2 ; 6$ & $6 ; 2$ \\
\hline
\end{tabular}

Table $A$

\begin{tabular}{|c|c|}
\hline \multicolumn{1}{c}{$A$} & $B$ \\
\hline $6 ; 2$ & $2 ; 6$ \\
\hline
\end{tabular}

Table $B$

Figure 4: Central situation of the experiment

There are two players, a sender and a receiver. In the beginning, the computer randomly selects one of the payoff tables $A$ and $B$, each with equal probability. Only the sender will be (correctly) informed which table has been selected. Next, the sender transmits either the message "Table A has been selected" or the message "Table B has been selected" to the receiver. Please, observe that the sender can transmit whatever message he prefers. After observing the sender's message, the receiver decides whether to take action $A$ (that is to select column $A$ ) or to take action $B$ (that is to select column $B$ ). The interpretation of the 
actions is that the receiver says either $I$ believe the actual payoff table is $A$ or I believe the actual payoff table is $B$. The payoffs to the sender and the receiver, which are given by the numbers in the corresponding cell, depend only on the table actually chosen by the computer and the action selected by the receiver. The first number in the cell corresponds to the payoff of the sender, the second number to the payoff of the receiver. In short, if the receiver's action matches with the actual table she receives 6 ECU (Experimental Currency Units) and the sender 2 ECU. Otherwise, payoffs are the opposite. For example, if the computer chooses table A, the sender tells the receiver that table A has been selected, and the receiver takes action $\mathrm{A}$, then the sender gets $2 \mathrm{ECU}$ and the receiver 6 ECU.

\section{Environment 2}

The second environment extends the first environment. After receiving feedback on the table chosen by the computer and the decisions of the sender and the receiver, the receiver has to make a final decision. She has to decide, given the potential payoff distribution corresponding to environment 1, whether to transfer 1 ECU of her/his payoff to the sender or to leave the payoffs as they are (that is, no transfer to take place).

\section{Matching}

This experimental session consists of 80 rounds. Before the first round, the computer divides all participating students into groups of twelve. Groups are not changed throughout the whole experiment and you will not know who else is in your group. In every round, the computer assigns you randomly to one of the two environments, each environment being equally likely. Next, you are randomly matched with another participant from your group and from the same environment to form a pair. In each pair, one participant is randomly chosen to be the sender, and one to be the receiver. Your profile may change every round with respect to three variables: the environment you are assigned to (1 or 2 ), the participant from your group you are matched with (some subject from the same environment), and the role you have (sender or receiver). The matching is anonymous, so you will never learn with whom you formed a pair. After every round you receive a complete feedback about the table that has been randomly chosen, the decisions of both players, your payoff, and your accumulate payoff.

\section{Payment}

The points that you accumulate in course of the experiment will determine your payment. The exchange rate ECU/Euros is such that every ECU in the experiments is equal to 4 Eurocents. Hence every 25 ECU will give you 1 Euros. 


\section{Closing}

At the end of the experiment, we would like to ask you to complete a short on-screen questionnaire. But, before we start, we would like to ask you to answer the control questions on the bottom of this page. Once ready, please raise your hand, and one of the experimenters will check your answers. The software will be started as soon as all answers have been checked. So, please, be patient.

Thank you again and good luck with the experiment! And, please, make your decisions carefully_your reward depends on your performance during the experiment.

\section{Control questions}

Please, answer the following questions! One of the experimenters will go round, check the answers and discuss any problems.

\begin{tabular}{|l|l|l|}
\hline Statement & True & False \\
\hline $\begin{array}{l}\text { In round } 43, \text { I will know in which environment I am going to be } \\
\text { in round } 44 .\end{array}$ & & \\
\hline $\begin{array}{l}\text { If I am playing the role of sender this round, I can be sure to be playing } \\
\text { the role as receiver next round. }\end{array}$ & & \\
\hline $\begin{array}{l}\text { I never know whom of the other participants I am matched with. } \\
\text { As a sender I can be sure that the receiver regards my message as } \\
\text { credible. }\end{array}$ & & \\
\hline $\begin{array}{l}\text { In the second environment, before making the decision of whether } \\
\text { or not to transfer } 1 \text { ECU to the sender, I am informed about the } \\
\text { selected table and the payoffs resulting from my choice as a receiver. }\end{array}$ & & \\
\hline \begin{tabular}{l} 
My decisions do not influence my payoffs. \\
\hline
\end{tabular} & & \\
\hline
\end{tabular}

